Original article

\title{
Influence of inner crown thickness on the bonding strength of porcelain fused to $\mathrm{Co}-\mathrm{Cr}$ alloy endocrown
}

\author{
Xuesheng Li \\ Department of Prosthodontics, Hainan Stomatological Hospital, Haikou, P. R. Chin
}

(Received June 20, 2021; Accepted October 2, 2021)

\begin{abstract}
Purpose: The purpose of this study was to investigate the influence of inner crown thickness on the bonding strength of porcelain fused to $\mathrm{Co}-\mathrm{Cr}$ alloy endocrown by shear strength test.

Methods: According to the molar average anatomical data to obtain a simplified model for endocrowns, porcelain fused to $\mathrm{Co}-\mathrm{Cr}$ alloy endocrowns were fabricated with four inner crown thicknesses: $0.3 \mathrm{~mm}, 0.5 \mathrm{~mm}, 0.8$ $\mathrm{mm}$, and $1.0 \mathrm{~mm}$ group, eight specimens were fabricated for each thickness group. Shear bond strength test was used to observe the metal-porcelain bonding strength, scanning electron microscope (SEM) and energy dispersive spectrometer (EDS) analysis were performed after the test to evaluate the interface of metal-porcelain.

Results: The shear bond strength means (in MPa) were: $10.50 \pm 2.55(0.3$ $\mathrm{mm}), 13.21 \pm 2.27(0.5 \mathrm{~mm}), 14.47 \pm 1.46(0.8 \mathrm{~mm})$, and $15.78 \pm 2.81$ $(1.0 \mathrm{~mm})$, one-way ANOVA showed that there was a statistically significant difference among the thicknesses $(P<0.05)$. The SEM observation showed tight bonding, and the EDS analysis showed element diffusion phenomenon at the metal-porcelain interface.

Conclusion: The bonding strength of porcelain fused to $\mathrm{Co}-\mathrm{Cr}$ alloy endocrown varied according to the different thickness of inner crown and the thinner inner crown was recommended for tooth defects with limited prosthodontic space.
\end{abstract}

Keywords: bonding strength, $\mathrm{Co}-\mathrm{Cr}$ alloy, endocrown, porcelain fused to metal crown

\section{Introduction}

A prosthesis is one of the most commonly used methods to repair tooth defects, and endocrown is one of them. The endocrown uses the pulp cavity of the tooth to make the restoration retentive and stable by bonding. At present, it is mainly used in the large area defects of posterior teeth after root canal treatment, such as the restoration of residual roots and crowns, and is especially suitable for the treatment of severe attrition, limited occlusal distance, and so on [1-3].

In the clinic, there are mainly three kinds of restorative materials for endocrown: composite resin, all ceramic and metal-porcelain [4-6]. The composite resin restoration has poor adaptation, is susceptible to adherence by plaque, and also to wear. All ceramic restoration has considerable attrition to natural teeth, and the high cost makes it difficult for patients to accept them. Metal-porcelain restoration, especially cobalt chromium alloy, is still one of the most commonly used crown restorations in the clinic because it is economical, has relatively ideal biocompatibility and aesthetic effects $[7,8]$.

However, the retention core and the edge of the endocrown have obvious differences, and the shrinkage rate of metal and porcelain is different after casting and sintering, which may affect the metal-porcelain bonding

Correspondence to Dr. Xuesheng Li, Department of Prosthodontics, Hainan Stomatologica Hospital, No. 50, Youyi Road, Haiken Street, Longhua District, Haikou, Hainan 570266, P. R. China E-mail: 442924722@qq.com

Color figures can be viewed in the online issue at J-STAGE.

doi.org/10.2334/josnusd.21-0288

DN/JST.JSTAGE/josnusd/21-0288 strength and lead to porcelain exfoliation or cracks (porcelain fracture) [9-11]. The purpose of this study was to investigate the influence of inner crown thickness on the bonding strength of porcelain fused to $\mathrm{Co}-\mathrm{Cr}$ alloy endocrown by shear strength test, scanning electron microscope and energy dispersive spectrometer.

\section{Materials and Methods}

\section{Establishment of study model}

Based on the average anatomical data of molars, a simplified stainless steel study model for endocrown was made (Fig. 1).

The simplified study model had two parts, the upper cover (A) and the base (B). There were four types of covers, different types of covers were positioned with the base, different edge gaps $(0.3,0.5,0.8$, and $1.0 \mathrm{~mm})$ (C) and one cavity retention core (D) could be obtained, porcelain was applied on D surface.

\section{Fabrication of wax specimen}

Dipping wax was put in the wax melting machine, heated to the molten liquid state, and filled slowly into the cavity of the base, then positioned in the different covers. Inner crowns with different thicknesses $(0.3,0.5,0.8$, and $1.0 \mathrm{~mm}$ ) could be obtained, 8 for each thickness, 32 in total.

\section{Investment casting}

Each wax pattern was checked for integrity, embedded, casted, and blasted with $100 \mu \mathrm{m}$ aluminum oxide particles from a distance of approximately $2.0 \mathrm{~cm}$ at $0.5 \mathrm{MPa}$ for $20 \mathrm{~s}$, and all specimens were washed in distilled water, dried and kept untouched until porcelain application.

\section{Porcelain application and sintering}

Following the manufacturer's guidelines, the inner crown was firstly applied with a thin bonding porcelain layer of $0.1 \mathrm{~mm}$. After firing, opaque porcelain was applied with a thinness of $0.2 \mathrm{~mm}$, then fired, and the coating the body porcelain Porcelain powder (VITA Zahnfabrik, Bad Sackingen, Germany) was $2.0 \mathrm{~mm}$. Shrinkage of the specimens was compensated for by applying a second layer. Finally, the specimens were submitted to final glaze firing. Porcelain application for all specimens was performed by a senior professional dental technician.

\section{Fabrication of metal-porcelain interface specimen}

One specimen was randomly selected from each thickness of the inner crown, and a total of 4 specimens were made for the metal-porcelain bonding interface. The specimens were completely embedded with epoxy resin and cut along with the mesial-distal distance by a slow cutting machine to expose the metal-porcelain interface. The metal-porcelain interface was polished by \#280-2,500 water abrasive paper, soft flannelette and paste. After cleaning, drying and carbon spraying, scanning electron microscope (SEM) and energy dispersive spectrometer (EDS) analysis were carried out. The analysis sites were at the middle and the edge of the specimen.

\section{Shear strength test}

The metal part of the remaining 28 specimens was embedded in self-cured acrylic resin independently, and only the porcelain part was exposed. Shear strength testing was performed in a universal testing machine (Chinese Academy of Sciences, Changchun, P. R. China) and loaded at a cross speed of $0.5 \mathrm{~mm} / \mathrm{min}$ according to previous studies until fracture. The shear 


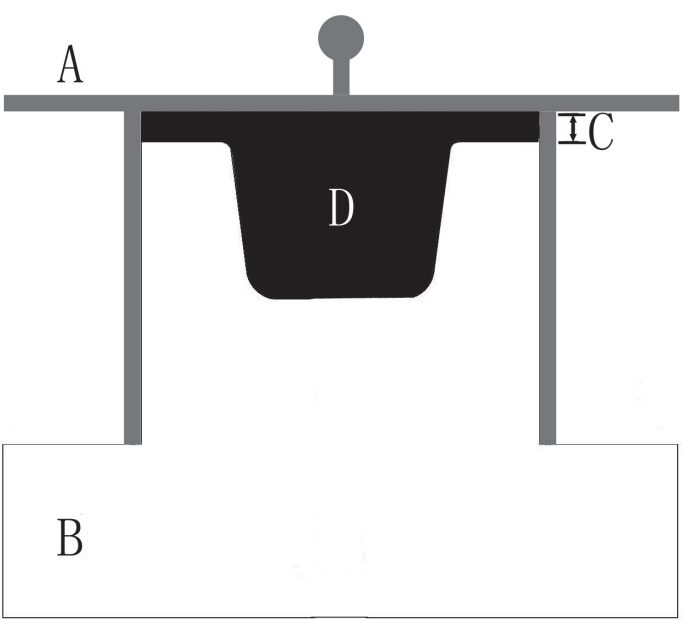

Fig. 1 Simplified study model for endocrown

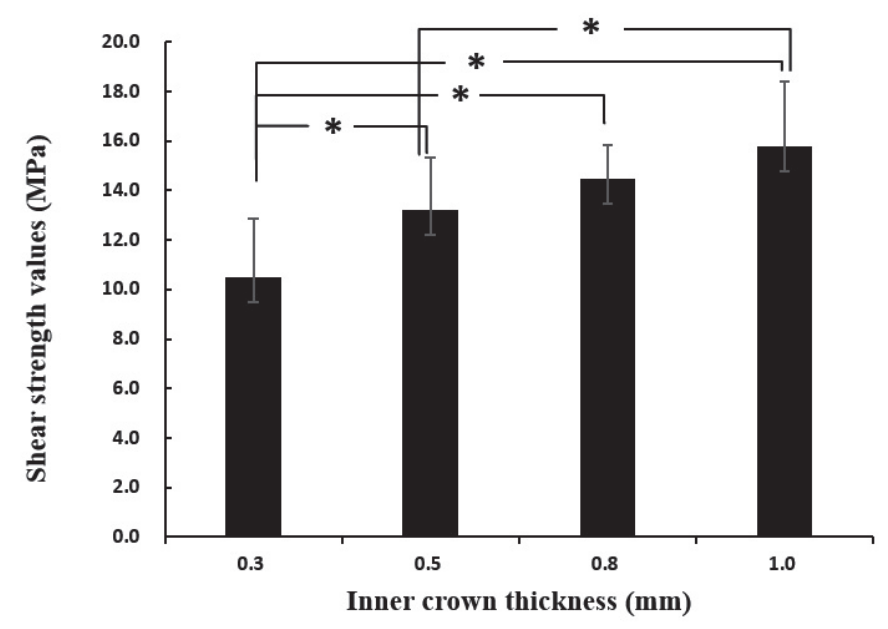

Fig. 2 Comparison of shear strength values in each group
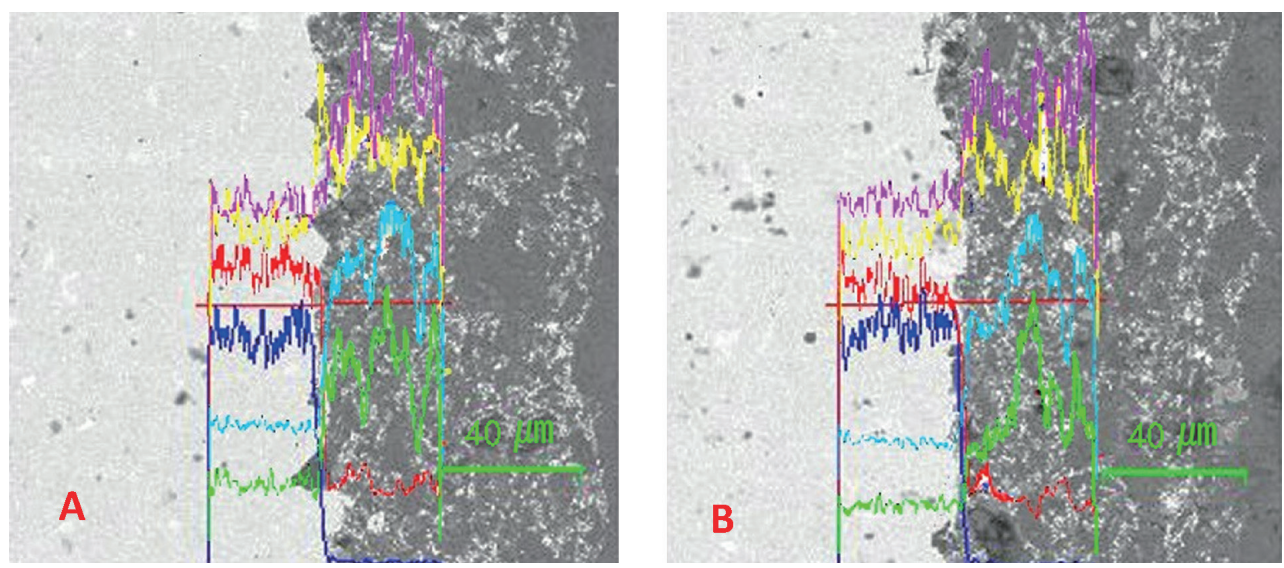

Fig. 3 EDS test different location of element diffusion distribution diagram $(\times 1,000)$, A: edge point; B: middle point

strength (in MPa) was calculated by dividing the maximum load by the cross-sectional area of the metal-porcelain.

In addition, one specimen of each thickness was randomly selected from the fracture specimens for SEM scanning and surface morphology analysis.

\section{Statistical analysis}

The bonding strength data of each thickness accorded with normal distribution and homogeneity of variance was compared by one-way ANOVA of SPSS 22 statistical software $(F=1.432, P=0.258) . P$-values less than 0.05 were considered to be statistically significant in all tests. When the ANOVA showed that there were statistical differences among groups, Bonferroni was compared.

\section{Results}

\section{Results of shear strength test}

Figure 2 shows shear strength test results. The variance showed that there was a statistical difference in the shear strength between the different thickness, Bonferroni showed that there were statistical differences between $0.5,0.8,1.0$, and $0.3 \mathrm{~mm}$, and also between 0.5 and $1.0 \mathrm{~mm}(P<0.05)$.

\section{Results of metal-porcelain interface for SEM test}

SEM (Carl Zeiss AG, Jena, Germany) scanning showed that the bonding interface of metal-porcelain was close, and that they were inlaid and locked with each other, and only small gaps and bubbles were occasionally seen, as shown in Fig. 3.

\section{Results of metal-porcelain interface for EDS test}

A vertical line was made at the metal-porcelain interface, EDS (Oxford
Instruments, Oxford, UK) scanning was carried out at the edge and the middle of the interface. It was found that the elements inside the metal and porcelain diffused mutually, and the main elements were $\mathrm{Cr}, \mathrm{Co}, \mathrm{O}, \mathrm{Na}$, $\mathrm{Si}, \mathrm{K}$. The interface elements are all gradient distribution, namely typical S-shaped diffusion, as shown in Fig. 3 (On the left side of the figure is the metal interface, on the right side is the porcelain interface; the blue line is the Co element, the red line is the Cr element, the yellow line is the o element, the purple line is the Na element, the blue line is the Si element, and the green line is the $\mathrm{K}$ element diffusion distribution).

\section{Results of visual inspection and SEM on the failure interface}

There were three main modes of failure interface observed under SEM at a low-power microscope. Cohesive failure (internal fracture), interface failure (fully exposed metal surface), mixed failure (exposed part of metal and porcelain) [12], the number of specimens of failure modes is shown in Table 1.

The failure interface of metal-porcelain was observed under SEM under a high-power microscope. The exposed area of metal (gray black) showed irregular, relatively rough, cracks, occasionally high ridges or were deeply concave. The exposed area of porcelain (gray white) showed that the surface structure was complex, extremely rough and irregular, with many cracks, and sharps, clear cross sections, as shown in Fig. 4.

\section{Discussion}

Porcelain fused to metal restorations is widely used in dental clinics at present. It is a kind of metal-porcelain composite restoration with low melting porcelain fused to the inner metal crown under the condition of high temperature and vacuum, which has high strength and strong aesthetics. The tight bonding of metal and porcelain has been an important factor 
Table 1 Fracture mode and number of specimens in each group

\begin{tabular}{llccc}
\hline Group & $n$ & Interface failure & Cohesive failure & Mixed failure \\
\hline 0.3 & 7 & 0 & 0 & 7 \\
0.5 & 7 & 0 & 0 & 7 \\
0.8 & 7 & 0 & 1 & 6 \\
1.0 & 7 & 0 & 1 & 6 \\
\hline
\end{tabular}
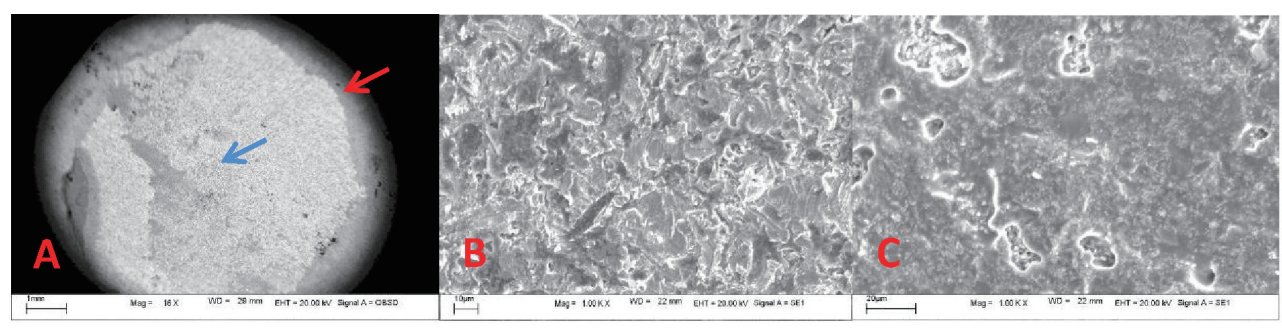

Fig. 4 Surface morphology of SEM scanning. A: holistic observation $(\times 16)$; B: edge point (red arrow) $(\times 1,000)$; C: middle point (blue arrow) $(\times 1,000)$

for the successful clinical application since the 1950s. However, in clinics, porcelain exfoliation and cracks (or porcelain fracture) are the main clinical manifestations of failure of porcelain fused to metal restoration, and it has been reported that the failure rate of both is as high as $34 \%$ [13]. Good bonding strength between metal and porcelain can ensure the compressive strength of restorations, and this is also the key to the long-term success of restoration $[14,15]$.

There are many methods to test the bonding of metal and porcelain, but there is no ideal standard method at present. Most researchers adopt different testing methods according to material properties, specimen size and shape, loading speed and direction. According to the stress produced in the test, the test methods can be divided into shear test, torsion test, tensile test, bending test, tension test, and so on $[16,17]$. In this study, because of the special shape of pulp retention, the shear force test was selected for use. The specimen of shear force test is not easily affected by friction and elastic modulus, and the test process is easy to operate, so the experimental results are more reliable [18].

The bonding strength of metal and porcelain is affected by many factors, such as incompatibility of the coefficient of thermal expansion between the porcelain and the metal structure, limited tooth reduction during preparation, the surface treatment of inner crown, inappropriate porcelain operation technology, excessively high sintering temperature, incorrect position and speed of specimen loading, and so on. In a previous study, the shear strength value of metal-porcelain bonding of different casting alloys was about 10-60 MPa $[19,20]$. The shear strength of metal-porcelain in this experiment was not high, which might have been caused by the special shape of the endocrown. The metal retention shape was large, while the edge metal was relatively thin, the thickness and shape of the inner crown were uneven and not uniform, which made it easy to affect residual stress and cause large deformation after sintering.

However, it can be seen from Fig. 2 that with the gradual increase of edge thickness, the morphological difference between edge and retention core was relatively small, and the less the metal deformation after casting, the greater the bonding strength value. There was a substantial difference in shear strength between the inner crowns with thickness of $0.5,1.0$, and $0.3 \mathrm{~mm}, 0.5$, and $1.0 \mathrm{~mm}$. According to the literature, when the shear strength reached above $10 \mathrm{MPa}$, porcelain exfoliation and cracks (or porcelain fracture) could be avoided in clinics, which could completely meet the clinical use requirements $[21,22]$.

In Fig. 3, SEM high-power microscope shows that the metal-porcelain interface was tight, metal and porcelain were inlaid and locked with each other, and only small gaps and bubbles were occasionally seen. EDS analysis indicated that the elements between metal and porcelain diffused with each other and the two interfaces were integrated, which was the key chemical combination of metal-porcelain. When tracing the main elements of alloy and porcelain, it was found that the concentration of $\mathrm{Cr}, \mathrm{Co}, \mathrm{O}$, $\mathrm{Na}, \mathrm{Si}, \mathrm{K}$ was diffused to the opposite side, and the concentration showed a significant downward trend, which was consistent with other reports of a typical S-shaped curve diffusion [23,24]. The migration of metal and porcelain elements, and the shear strength value in Table 1 shows that the Co-Cr alloy endocrown obtained a good bond strength.

In Fig. 4, under SEM low-power microscope observation, there is more gray white porcelain in the middle of the damaged specimen, and more gray black metals were exposed on the edge, which indicated that the bonding ability at the edge was weak, while in the middle it was good. According to the analysis of the special shape of the endocrown, the metal at the edge was much thinner than that at the middle (core), and it was easy to deform after casting, which easily lead to failure of the specimen at the edge rather than in the middle. In addition, most of the specimens showed mixed failure under SEM low-power microscope, and only a few of the specimens showed complete separation, which indicated that the combination of metal and porcelain was very close, and this was consistent with the research of Diniz AC, Henriques, Swain and other researchers [12,21,25].

According to the SEM high-power microscope observation in Fig. 4, the exposed metal was irregular, and relatively rough, with visible cracks. Occasionally, there were high ridges or deep pits. The surface structure of the porcelain layer is complex, extremely rough, had many cracks, and the fracture surface was sharp and clear. This suggested that the mechanical locking between the metal and the porcelain interface was good, and was also a physical combination.

Within the limitations of this study, the following conclusions were drawn: the bonding strength of metal and porcelain of $\mathrm{Co}-\mathrm{Cr}$ alloy endocrown with the thickness of $0.3,0.5,0.8$, and $1.0 \mathrm{~mm}$ can meet clinical requirements in clinics, and doctors can select and apply it on the basis of the actual situation. However, considering the restoration space, the thinner inner crown can be highly recommended when the occlusal space is limited or the teeth are severely worn.

\section{Conflict of interest}

The author declares no conflict of interest.

\section{References}

1. Tzimas K, Tsiafitsa M, Gerasimou P, Tsitrou E (2018) Endocrown restorations for extensively damaged posterior teeth: clinical performance of three cases. Restor Dent Endod 43 , e38.

2. Dogui H, Abdelmalek F, Amor A, Douki N (2018) Endocrown: an alternative approach for restoring endodontically treated molars with large coronal destruction. Case Rep Dent 2018, 1581952

3. Govare N, Contrepois M (2020) Endocrowns: a systematic review. J Prosthet Dent 123 , 411-418. e9.

4. Sedrez-Porto JA, Münchow EA, Valente LL, Cenci MS, Pereira-Cenci T (2019) New material perspective for endocrown restorations: effects on mechanical performance and fracture behavior. Braz Oral Res 33, e012.

5. Alhazzani SA, Aldossary MS (2019) Metal endocrown approach for a maxillary second molar: a novel technique. Gen Dent 67, 67-71.

6. El Ghoul WA, Özcan M, Ounsi H, Tohme H, Salameh Z (2020) Effect of different CADCAM materials on the marginal and internal adaptation of endocrown restorations: an in vitro study. J Prosthet Dent 123, 128-134.

7. Grimaudo NJ (2001) Biocompatibility of nickel and cobalt dental alloys. Gen Dent 49, 498-503.

8. Al Jabbari YS (2014) Physico-mechanical properties and prosthodontic applications of Co-Cr dental alloys: a review of the literature. J Adv Prosthodont 6, 138-145. 
9. Anusavice KJ, Hojjatie B, Dehoff PH (1986) Influence of metal thickness on stress distribution in metal-ceramic crowns. J Dent Res 65, 1173-1178.

10. Ekren O, Ozkomur A, Ucar Y (2018) Effect of layered manufacturing techniques, alloy powders, and layer thickness on metal-ceramic bond strength. J Prosthet Dent 119, 481487.

11. Kaleli N, Ural Ç, Özköylü G, Duran İ (2019) Effect of layer thickness on the marginal and internal adaptation of laser-sintered metal frameworks. J Prosthet Dent 121, 922-928.

12. Diniz AC, Nascimento RM, Souza JC, Henriques BB, Carreiro AF (2014) Fracture and shear bond strength analyses of different dental veneering ceramics to zirconia. Mater Sci Eng C Mater Biol Appl 38, 79-84.

13. Heintze SD, Rousson V (2010) Survival of zirconia- and metal-supported fixed dental prostheses: a systematic review. Int J Prosthodont 23, 493-502

14. Benetti P, Pelogia F, Valandro LF, Bottino MA, Bona AD (2011) The effect of porcelain thickness and surface liner application on the fracture behavior of a ceramic system. Dent Mater 27, 948-953.

15. Henriques B, Soares D, Silva FS (2012) Microstructure, hardness, corrosion resistance and porcelain shear bond strength comparison between cast and hot pressed CoCrMo alloy for metal-ceramic dental restorations. J Mech Behav Biomed Mater 12, 83-92.

16. Toptan F, Alves AC, Henriques B, Souza JC, Coelho R, Silva FS et al. (2013) Influence of the processing route of porcelain/Ti-6Al-4V interfaces on shear bond strength. J Mech Behav Biomed Mater 20, 327-337.

17. Lima JM, Souza AC, Anami LC, Bottino MA, Melo RM, Souza RO (2013) Effects of thickness, processing technique, and cooling rate protocol on the flexural strength of a bilayer ceramic system. Dent Mater 29, 1063-1072.

18. Ereifej N, Rodrigues FP, Silikas N, Watts DC (2011) Experimental and FE shear-bonding strength at core/veneer interfaces in bilayered ceramics. Dent Mater 27, 590-597.

19. Fernandes Neto AJ, Panzeri H, Neves FD, Prado RA, Mendonça G (2006) Bond strength of three dental porcelains to Ni-Cr and Co-Cr-Ti alloys. Braz Dent J 17, 24-28.

20. Abi-Rached Fde O, Fonseca RG, Haneda IG, de Almeida-Júnior AA, Adabo GL (2012) The effect of different surface treatments on the shear bond strength of luting cements to titanium. J Prosthet Dent 108, 370-376.

21. Henriques B, Soares D, Silva FS (2011) Shear bond strength of a hot pressed Au-Pd-Pt alloy-porcelain dental composite. J Mech Behav Biomed Mater 4, 1718-1726.

22. Serra-Prat J, Cano-Batalla J, Cabratosa-Termes J, Figueras-Àlvarez O (2014) Adhesion of dental Porcelain to cast, milled, and laser-sintered cobalt-chro-mium alloys: shear bond strength and sensitivity to thermocycling. J Prosthet Dent 112, 600-605.

23. Vásquez VZ, Ozcan M, Kimpara ET (2009) Evaluation of interface characterization and adhesion of glass ceramics to commercially pure titanium and gold alloy after thermal- and mechanical-loading. Dent Mater 25, 221-231.

24. Henriques B, Gasik M, Soares D, Silva FS (2012) Experimental evaluation of the bond strength between a CoCrMo dental alloy and porcelain through a composite metal-ceramic graded transition interlayer. J Mech Behav Biomed Mater 13, 206-214.

25. Swain MV (2009) Unstable cracking (chipping) of veneering porcelain on all-ceramic dental crowns and fixed partial dentures. Acta Biomater 5, 1668-1677. 